\title{
Effects of LAs' Strategic Bidding on Wholesale Electricity Market Equilibrium
}

\author{
Iman Taheri ${ }^{1}$, Hossein Askarian Abyaneh ${ }^{1, *}$, Seyed Hossein Hosseinian ${ }^{1}$ and Alireza Bakhshai ${ }^{2}$ \\ 1 Amir Kabir University of Technology, Tehran, Iran; i.thri@aut.ac.ir; askarian@aut.ac.ir; hosseinian@aut.ac.ir \\ 2 Queen's University; alireza.bakhshai@queensu.ca \\ * Correspondence: askarian@aut.ac.ir;
}

\begin{abstract}
This paper proposes a game-theoretic framework for quantifying effects of strategic bidding behavior of load aggregators (LAs) on wholesale electricity market equilibrium. The independent system operator (ISO) employs double-sided auction design to settle transactions in the wholesale electricity market. Generating companies (GENCOs) and LAs submit their bids to the ISO in the economic model of supply function equilibrium. Under the smart grid paradigm, a LA participates in the electricity market on behalf of end-consumers to minimize their total payment for purchasing electricity. In this paper, bi-level programming (BLP) method is employed to determine optimal bidding strategy of self-interested market participants. In the upper level, the profit of intended market participant is maximized and in the lower level, the ISO clears the market via a bid-based transmission constrained economic dispatch (TCED). Also, competition of GENCOs and LAs is modeled as a non-cooperative game. To examine the effects of strategic bidding behavior of LAs on market equilibrium, the proposed model is applied to the IEEE 9-bus test system. According to numerical results, to allow the LAs to behave strategically along with the GENCOs makes the former better off and the latter worse off, while the net effect of this on total social welfare turns out to be case-contingent.
\end{abstract}

Keywords: imperfect competition; wholesale electricity market; non-cooperative game theory, smart grid; optimal bidding strategy

\section{Introduction}

One of the most important results of emerging smart grids is active participation of demand-side players in wholesale electricity markets [1]. Active participation of demand-side players in wholesale electricity markets can provide benefits such as improvement of market efficiency, mitigation of market power, reduction of the electricity price volatility, enhancement of grid reliability, and reduction of the need for grid reinforcements [2]. According to the aforementioned descriptions, modeling the bidding behavior of demand-side players in the wholesale electricity market and analyzing its effects on market equilibrium are crucial issues under smart grid paradigm.

Before emerging smart grids, end-consumers pay at flat rates. Because of this, end-consumers do not have enough motivation to response to the electricity price variations [3]. The advent of smart grids with intelligent controls and availability of a two-way communications network, allows end-consumers to adjust their consumption in response to a market signal by curtailing load, shifting load to off-peak periods, or running on-site generation resources [4]. Under smart grid paradigm, end-consumers can be divided into two types of flexible and inflexible loads [5]. Inflexible loads are assumed to be inelastic and are set at a fixed value, regardless of the market price. For example, some residential loads such as lighting, air conditioning, etc. could not be curtailed or shifted to other periods. Also, the commercial loads that need a certain amount of electrical energy in a certain time have weak responses to the electricity price variations. Unlike fixed hourly loads, flexible loads can change their electricity consumption, according to the electricity price [6]. For example, the industrial consumers who generate their own power have active responses to the 
electricity price variations. This type of industrial consumers uses onsite generation to response price variations. In this case, intended customers may experience no or very little change in their electricity consumption pattern; however, from view point of the ISO, consumption of the industrial consumers will reduce significantly. Also the flexible portion of residential consumers such as dish washer, clothes washer/dryer, and electric vehicles can respond to high electricity prices by delaying their start time. According to aforementioned descriptions, the initiation of smart grids allows a flexible load to submit bid for MWs that are sensitive to electricity price [7]. The end-consumers have an option to participate in the electricity market either individually or in an organized manner. Practically, the end-consumers do not have enough size to participate directly in the wholesale electricity markets. End-consumers would likely participate in the wholesale electricity markets via a LA [8]. The LA is an intermediary between the end consumers and the wholesale electricity market. The LA could be an independent for-profit organization or non-profit organization. In [9], a hierarchical market structure is proposed which facilitates the participation of end customers in the electricity markets. In [9], the LA plays on behalf of its consumers in both distribution network electricity market and wholesale electricity market. In [9], the objective of the LA is to minimize the cost of the electricity purchased from wholesale electricity market. In [10], the aggregator was considered to be a financial entity responsible for gathering residential and commercial consumers, in order to maximize its profit in the electricity market and decrease the consumers retailing price.

Due to limited number of market participants, restructured power markets are not perfectly competitive than they are more similar to oligopoly. In oligopolistic environment, a strategic participant has the ability to profitably manipulate the market outcome through exercising market power, or in other words, through strategic bidding. It is reasonable to assume that oligopolistic competition of electricity market participants eventually lead to an economic equilibrium [11]. Therefore, equilibrium-based methods have become a natural framework to study strategic behavior of electricity market participants. The commonest approaches for determining equilibrium of oligopolistic wholesale electricity markets are based on game theory (GT). These approaches, which may be used by the market participants to maximize their profits, vary among different market designs. Wholesale electricity markets can be designed to perform a single-sided or double-sided auction. Single-sided auctions allow only GENCOs bid while double-sided auctions allow both GENCOs and demands to submit bids [12]. In [13], bidding behaviors of suppliers in a single-sided auction modeled as a non-cooperative game with complete information. In [14], non-cooperative game with incomplete information is employed to determine optimal bidding strategy of a GENCO when he is uncertain about bids of rival GENCOs. However, the load reduction capacity of a LA can be considered as equivalent generation resource on the wholesale electricity market. The double-sided auctions allow LAs to participate in the wholesale electricity price setting process. Depending on the level of market power, LAs can be classified into non-strategic and strategic LAs, in increasing order of market power. Non-strategic LAs are price taker and bid their marginal revenues. A non-strategic LA will decrease demand down when the market price is higher than average and vice versa. The basic idea in the application of non-strategic LAs is to reduce consumers' payment and price spikes [15]. Ref [16] carried out in-depth study into the effects of demand elasticity on the electricity market efficiency. Ref [17] examined price elasticity of demands using a matrix of self and cross elasticity and then studied its impact on electricity prices. Ref [18] simulated a dynamic double-sided auction and then showed that price-responsive loads can enhance the market efficiency. While numerous papers are concerned with optimizing bidding strategy of GENCOs, only a limited number of studies explored demand-side bidding from view point of a strategic LA. It is worth mentioning that a LA needs to aggregate an important number of end-consumers to be able profitably manipulate the market outcome by its bids. Ref [19] proposed a heuristic method that determines optimal bidding curve of a large consumer. In [20], authors examined the inclusion of demand side bidding in wholesale energy market to study economic aspects of coordinated bidding policies of demands in market equilibrium. Ref [21] calculated optimal bidding strategy of a Norwegian electricity purchaser considering demand uncertainty. Ref 
[22] determined the optimal bidding strategy of a retailer who participates in the Spanish day-ahead and intraday markets.

In this paper, LAs are considered as non-profit organizations who participate in the wholesale electricity market on behalf of end-consumers. A LA has the responsibility of coordinating its consumers' behavior in the wholesale electricity market. Under smart grid paradigm, the wholesale electricity market consists of GENCOs and LAs. However, GENCOs seek to increase the electricity price whereas LAs seek to decrease the electricity price. In this paper, bidding behavior of a strategic market participant is formulated as a BLP problem. In the upper level, the profit of intended market participant is maximized; in the lower level, the wholesale electricity market is optimally cleared by the ISO considering transmission constraints, power generation limits of GENCOs, and consumption limits of LAs. The market clearing process is modeled as a quadratic programming (QP) problem. Also, competition of GENCOs and LAs is modeled as a non-cooperative game and the market equilibrium is derived via calculating Nash Equilibrium (NE). A major contribution of this paper is to quantify how the market equilibrium is changed when a few strategic LAs and a number of price takers participate in the wholesale electricity market on behalf of end-consumers.

\section{Electricity Market Settlement}

In this paper, double-sided auction mechanism employs to settle transactions in the wholesale electricity market. Bids of market participants and clearing process of wholesale electricity market are formulated in following sections.

\subsection{Bids of GENCOs in the Wholesale Electricity Market}

Assuming generation cost of GENCO $\mathrm{j}$ can be represented by a quadratic function that depends on the output power $\mathrm{Pg}$, as follows:

$$
C_{j}\left(P_{g j}\right)=\frac{1}{2} a_{j} P_{g j}^{2}+b_{j} P_{g j}+c_{j}
$$

Where $a_{j}, b_{j}$, and $c_{j}$ are the generation cost coefficients. So short-term marginal cost of GENCO $j$ is:

$$
M C_{j}\left(P_{g j}\right)=a_{j} P_{g j}+b_{j}
$$

In (2), the marginal cost of GENCO $\mathrm{j}$ is monotonically increasing as a function of the output power $\mathrm{P}_{\mathrm{g} \text {. }}$. Since competition of GENCOs occurs in oligopolistic market, it is assumed that market participants submit their bids in economic model of linear SFE. In linear SFE model, GENCO $j$ adjusts both the slope and the intercept of its inverse supply function in a fixed relationship as the one between the slope and intercept of its marginal cost. We suppose that GENCO $j$ will submit bid to the ISO as:

$$
\rho_{j}\left(P_{g j}\right)=k_{j}\left(a_{j} P_{g j}+b_{j}\right)
$$

Where $k_{j}$ represents the bidding strategy adopted by the GENCO $j$ to submit in the wholesale electricity market.

\subsection{Offers of LAs in the Wholesale Electricity Market}

A LA aggregates offers of both flexible and inflexible end-consumers so that its aggregated offer in the wholesale electricity auction taking into account all preferences of end-consumers. As mentioned before, demand of an inflexible end-consumer is set at a fixed value, regardless of the market price. Also, offer of a flexible end-consumer identifies how much load it is willing to decrease at different prices. Using the flexibility offered by the end-consumers, the LAs can make load reductions, which is equivalent to generation capacity in terms of balancing power on the electricity market. It should be noted that the load reduction capacity of a LA is dependent on the number of flexible loads it controls. According to aforementioned descriptions, we suppose that the LA i will submit offer to the ISO, as follows:

$$
\theta_{i}\left(P_{d i}\right)=\kappa_{i}\left(-\alpha_{i} P_{d i}+\beta_{i}\right)
$$


Where $P_{\mathrm{di}}, \alpha_{\mathrm{i}}$, and $\beta_{\mathrm{i}}$ are the purchased power by the LA $\mathrm{i}$, the slope and intercept of aggregated inverse demand function of the LA $i$, respectively. In $(4),\left(-1 / \alpha_{i}\right)$ represents the price elasticity of the LA i. As would be expected, in (4) the offered price of the LA is monotonically decreasing as a function of the demand Pdi. Also, $\kappa_{i}$ represents the bidding strategy of the LA $\mathrm{i}\left(k_{i} \leq 1\right)$. Non-strategic demands are price-takers which are satisfied at the market clearing price $\left(\kappa_{i}=1\right)$.

\subsection{The Wholesale Electricity Market Clearing Mechanism}

In a pool-based electricity market, GENCOs and LAs submit their bids to the ISO which in turn, the ISO clears the wholesale electricity market on the basis of a merit order mechanism so that the social welfare is maximized. Note that since the true marginal benefits of demands and true marginal costs of GENCOs are unknown, the objective of the ISO is to maximize the quasi social welfare, as follows [23-24]:

$$
\operatorname{SW}\left(P_{g i}, P_{d i}\right)=\sum_{i=1}^{N_{d}} \kappa_{i}\left(-\alpha_{i} P_{d i}+\beta_{i}\right) P_{d i}-\sum_{j=1}^{N_{g}} k_{j}\left(a_{j} P_{g j}+b_{j}\right) P_{g j},
$$

Where $\mathrm{N}_{\mathrm{d}}$, and $\mathrm{N}_{\mathrm{g}}$ are the number of LAs and GENCOs, respectively. In order to express the objective function of the ISO in the standard form, minimizing the negative of the quasi social welfare is utilized instead of maximizing the quasi social welfare. Consequently, the market clearing problem can be formulated as the following quadratic minimization:

$$
\operatorname{Min}\left\{f\left(\boldsymbol{P}_{g}, \boldsymbol{P}_{d}\right)=\sum_{j=1}^{N_{g}} k_{j}\left(a_{j} P_{g j}+b_{j}\right) P_{g j}+\sum_{i=1}^{N_{d}} \kappa_{i}\left(\alpha_{i} P_{d i}-\beta_{i}\right) P_{d i}\right\},
$$

Subject to:

$$
\begin{gathered}
\sum_{i=1}^{N_{d}} P_{d i}-\sum_{j=1}^{N_{g}} P_{g j}=0, \\
P_{g j}^{\text {min }} \leq P_{g j} \leq P_{g j}^{\max } ; j=1 \ldots N_{g} \\
P_{d i}^{\min } \leq P_{d i} \leq P_{d i}^{\max } ; i=1 \ldots N_{d \prime} \\
-F_{l, \text { max }} \leq\left\{f_{l}=\sum_{i=1}^{N} T_{l i}\left(P_{g i}-P_{d i}\right)\right\} \leq F_{l, \text { max }} ; l=1 \ldots N_{l},
\end{gathered}
$$

Where $\mathrm{N}$, and $\mathrm{N}_{1}$ are the number of buses, and transmission lines, respectively. In (6), the equality constraint reflects the power balance constraint. Also, inequality constraints (4-c) and (4-d) consider generation capacity limits of GENCOs, consumption limits of LAs, and flow constraints of transmission lines, respectively. In (6-c), $P_{g j}^{\min }$ and $P_{g j}^{\max }$ represent the minimum and maximum generation limits of GENCO j, respectively. In (6-d), $P_{d i}^{\min }$ and $P_{d i}^{\max }$ represent the minimum and maximum demand of LA i, respectively. In (6-e), $f i$ represent the power flow of the line $1 . \operatorname{In}(6-\mathrm{e}), \mathbf{T}$ is power transfer distribution factor (PTDF) matrix with $\mathrm{T}_{\mathrm{li}}$ as an element; $\mathrm{T}_{\mathrm{li}}$ represents the sensitivity of the flow on line 1 to a change in the nodal injection at bus $i$ and the withdrawal of an equal active power at the reference bus.

In this paper, the barrier method is employed to approximate the inequality-constrained optimization problem in (6) by equality-constrained problem [25]. By incorporating the nonnegative slack variables $\omega>0, s>0$ into the logarithmic barrier functions, inequality constrained optimization in (6) is transformed into equivalent equality constrained optimization, as follows:

$$
\text { Min } f\left(\boldsymbol{P}_{g}, \boldsymbol{P}_{d}\right)-\eta \sum_{i=1}^{2 N_{g}+2 N_{d}} \ln \left(\omega_{i}\right)-\gamma \sum_{l=1}^{2 N_{l}} \ln \left(s_{l}\right),
$$

Subject to:

$$
\begin{gathered}
G\left(\boldsymbol{P}_{g}, \boldsymbol{P}_{d}\right)=0 \\
\boldsymbol{H}\left(\boldsymbol{P}_{g}, \boldsymbol{P}_{d}\right)+\boldsymbol{\omega}=0 \\
\boldsymbol{F}\left(\boldsymbol{P}_{g}, \boldsymbol{P}_{d}\right)+\boldsymbol{s}=0
\end{gathered}
$$

Where: 


$$
\begin{aligned}
& \mathbf{H}=\left[\begin{array}{ll}
\boldsymbol{H}_{g} & \boldsymbol{H}_{d}
\end{array}\right]^{T} ; \\
& \boldsymbol{H}_{g}=\left[\begin{array}{lllll}
h_{g 1} & \ldots & h_{g i} & \ldots & h_{2 N_{g}}
\end{array}\right]^{T} ; \\
& h_{g i}=P_{g i}^{\min }-P_{g i} ; i=1 \ldots N_{g} \\
& h_{g i}=-P_{g i}^{\max }+P_{g i} ; i=N_{g}+1 \ldots 2 N_{g} \\
& \boldsymbol{H}_{d}=\left[\begin{array}{lllll}
h_{d 1} & \ldots & h_{d i} & \ldots & h_{2 N_{d}}
\end{array}\right]^{T} ; \\
& h_{d i}=P_{d i}^{\min }-P_{d i} ; i=1 \ldots N_{d} \\
& h_{d i}=-P_{d i}^{\max }+P_{d i} ; i=N_{d}+1 \ldots 2 N_{d}
\end{aligned}
$$

$$
\begin{gathered}
\boldsymbol{\omega}=\left[\begin{array}{llll}
\boldsymbol{\omega}_{g} & \boldsymbol{\omega}_{d}
\end{array}\right]^{T} ; \\
\boldsymbol{\omega}_{g}=\left[\begin{array}{lllll}
\omega_{g 1} & \ldots & \omega_{g i} & \ldots & \omega_{2 N_{g}}
\end{array}\right]^{T} ; \\
\boldsymbol{\omega}_{d}=\left[\begin{array}{lllll}
\omega_{d 1} & \ldots & \omega_{d i} & \ldots & \omega_{2 N_{d}}
\end{array}\right]^{T} ; \\
\mathbf{s}=\left[\begin{array}{lllll}
\mathrm{S}_{1} & \ldots & s_{l} & \ldots & \mathrm{s}_{2 N_{l}}
\end{array}\right]^{T} ; \\
\mathbf{F}=\left[\begin{array}{lllll}
F_{1} & \ldots & F_{l} & \ldots & F_{2 N_{l}}
\end{array}\right]^{T} ; \\
F_{l}=f_{l}-F_{l, \text { max }} ; l=1 \ldots N_{l} \\
F_{l}=-f_{l}-F_{l, \text { max }} ; l=N_{l}+1 \ldots 2 N_{l}
\end{gathered}
$$

Where $\eta>0$ and $\gamma>0$ are the barrier parameters. According to (7), by adding the logarithmic barrier functions to the objective function of inequality-constrained optimization problem, minimizer of equality-constrained problem favors points interior to the feasible region (defined by inequality constraints (6-c), (6-d), (6-e)) over those near the boundary [26]. For this reason, the technique is called an interior point method. However, for equality-constrained optimization problem (7) the Lagrangian is defined by:

$$
\begin{gathered}
\mathrm{L}(\mathbf{t})=f\left(\boldsymbol{P}_{g}, \boldsymbol{P}_{d}\right)+\lambda G\left(\boldsymbol{P}_{g}, \boldsymbol{P}_{d}\right)+\boldsymbol{v}^{T}\left(\boldsymbol{H}\left(\boldsymbol{P}_{g}, \boldsymbol{P}_{d}\right)+\boldsymbol{\omega}\right)+\boldsymbol{\mu}^{T}\left(\boldsymbol{F}\left(\boldsymbol{P}_{g}, \boldsymbol{P}_{d}\right)+\boldsymbol{s}\right)- \\
\eta \sum_{i=1}^{2 N_{g}+2 N_{d}} \ln \left(\omega_{i}\right)-\gamma \sum_{l=1}^{2 l_{l}} \ln \left(s_{l}\right),
\end{gathered}
$$

Where $\mathbf{t}=\left[\mathbf{P}_{\mathrm{g}}, \mathbf{P}_{\mathrm{d}}, \lambda, \boldsymbol{v}, \boldsymbol{\mu}\right]^{\mathrm{T}}$; also, $\lambda, \boldsymbol{v}$, and $\boldsymbol{\mu}$ are the vectors of the Lagrange multipliers corresponding to $\mathrm{G}\left(\mathbf{P}_{\mathrm{g}}, \mathbf{P}_{\mathrm{d}}\right), \mathbf{H}\left(\mathbf{P}_{\mathrm{g}}, \mathbf{P}_{\mathrm{d}}\right)+\boldsymbol{\omega}$, and $\mathbf{F}\left(\mathbf{P}_{\mathrm{g}}, \mathbf{P}_{\mathrm{d}}\right)+\mathbf{s}$, respectively. The Karush-Kuhn-Tucker (K.K.T.) optimality conditions of the barrier problem are:

$$
\begin{gathered}
\frac{\partial \mathrm{L}(\mathrm{t})}{\partial \boldsymbol{P}_{g}}=\nabla_{\boldsymbol{P}_{g}} f+\lambda \nabla_{\boldsymbol{P}_{g}} G+\boldsymbol{v}^{T} \nabla_{\boldsymbol{P}_{g}} \boldsymbol{H}+\boldsymbol{\mu}^{T} \nabla_{\boldsymbol{P}_{g}} \boldsymbol{F}=\mathbf{0}, \\
\frac{\partial \mathrm{L}(\mathbf{t})}{\partial \boldsymbol{P}_{d}}=\nabla_{\boldsymbol{P}_{d}} f+\lambda \nabla_{\boldsymbol{P}_{d}} G+\boldsymbol{v}^{T} \nabla_{\boldsymbol{P}_{d}} \boldsymbol{H}+\boldsymbol{\mu}^{T} \nabla_{\boldsymbol{P}_{d}} \boldsymbol{F}=\mathbf{0}, \\
\frac{\partial \mathrm{L}(\mathbf{t})}{\partial \lambda}=G\left(\boldsymbol{P}_{g}, \boldsymbol{P}_{d}\right)=\mathbf{0}, \\
\frac{\partial \mathrm{L}(\mathbf{t})}{\partial \boldsymbol{v}}=\boldsymbol{H}\left(\boldsymbol{P}_{g}, \boldsymbol{P}_{d}\right)+\boldsymbol{\omega}=\mathbf{0}, \\
\frac{\partial \mathrm{L}(\mathbf{t})}{\partial \boldsymbol{\mu}}=\boldsymbol{F}\left(\boldsymbol{P}_{g}, \boldsymbol{P}_{d}\right)+\boldsymbol{s}=\mathbf{0}, \\
\frac{\partial \mathrm{L}(\mathbf{t})}{\partial \boldsymbol{\omega}}=\langle\boldsymbol{v}\rangle \boldsymbol{\omega}-\eta \boldsymbol{e}=\mathbf{0}, \\
\frac{\partial \mathrm{L}(\mathbf{t})}{\partial \boldsymbol{s}}=\langle\boldsymbol{\mu}\rangle \boldsymbol{s}-\eta \boldsymbol{e}^{\prime}=\mathbf{0},
\end{gathered}
$$

Where $\langle\boldsymbol{v}\rangle=\operatorname{diag}(\boldsymbol{v}),\langle\boldsymbol{\mu}\rangle=\operatorname{diag}(\boldsymbol{\mu}), \boldsymbol{e}=\left[\begin{array}{lll}1 & \ldots & 1\end{array}\right]_{N_{g d}}^{T}, \boldsymbol{e}^{\prime}=\left[\begin{array}{lll}1 & \ldots & 1\end{array}\right]_{2 N_{l^{\prime}}}^{T}$, and $N_{g d}=2 N_{g}+$ $2 N_{d}$. It should be noted that equations (9-a) and (9-b) are first-order necessary conditions for non-linear equality-constrained problem in (7). Because of the logarithmic terms in the objective function (7-a), the first-order necessary conditions are not sufficient. Also, second-order sufficient conditions are considered in (9-c), (9-d) and (9-e). Equations (9-f) and (9-e) represent complementary slackness conditions. The complementary slackness conditions formulate the fact that an inequality constraint is either active or inactive [21]. If an inequality constraint is binding (nonbinding), it belongs to the set of active constraints (inactive constraints). According to aforementioned descriptions, PDIPM works simultaneously with primal and dual variables in order to determine optimal solution of QP problem in (6). Whoever, the K.K.T. conditions are solved simultaneously by using Newton's method, as follows:

$$
\left[\nabla_{t}^{2} L\right] \Delta t=-\nabla_{t} L
$$

Where: 


$$
\begin{gathered}
\Delta \boldsymbol{t}=\left[\begin{array}{lccccccc}
\Delta \boldsymbol{P}_{g} & \Delta \boldsymbol{P}_{d} & \Delta \lambda & \Delta \boldsymbol{v} & \Delta \boldsymbol{\mu} & \Delta \boldsymbol{\omega} & \Delta \boldsymbol{s}
\end{array}\right]^{T}, \\
\nabla_{\boldsymbol{t}} L=\left[\begin{array}{lllllllll}
\nabla_{\boldsymbol{P}_{g}} L & \nabla_{\boldsymbol{P}_{d}} L & G\left(\boldsymbol{P}_{g}, \boldsymbol{P}_{d}\right) & \boldsymbol{H}\left(\boldsymbol{P}_{g}, \boldsymbol{P}_{d}\right)+\boldsymbol{\omega} & \boldsymbol{F}\left(\boldsymbol{P}_{g}, \boldsymbol{P}_{d}\right)+\boldsymbol{s} & \langle\boldsymbol{v}\rangle \boldsymbol{\omega}-\eta \boldsymbol{e} & \Delta \boldsymbol{s}
\end{array}\right]^{T}, \\
\nabla_{\boldsymbol{t}}^{2} L=\left[\begin{array}{ccccccccc}
\nabla_{\boldsymbol{P}_{g}}^{2} f & 0 & \nabla_{\boldsymbol{P}_{g}} G & \left(\nabla_{\boldsymbol{P}_{g}} \boldsymbol{H}\right)^{T} & \left(\nabla_{\boldsymbol{P}_{g}} \boldsymbol{F}\right)^{T} & 0 & 0 \\
0 & \nabla_{\boldsymbol{P}_{d}}^{2} f & \nabla_{\boldsymbol{P}_{d}} G & \left(\nabla_{\boldsymbol{P}_{d}} \boldsymbol{H}\right)^{T} & \left(\nabla_{\boldsymbol{P}_{d}} \boldsymbol{F}\right)^{T} & 0 & 0 \\
\left(\nabla_{\boldsymbol{P}_{g}} G\right)^{T} & \left(\nabla_{\boldsymbol{P}_{d}} G\right)^{T} & 0 & 0 & 0 & 0 & 0 & \\
\nabla_{\boldsymbol{P}_{g}} \boldsymbol{H} & \nabla_{\boldsymbol{P}_{d}} \boldsymbol{H} & 0 & 0 & 0 & I & 0 & \\
\nabla_{\boldsymbol{P}_{g}} \boldsymbol{F} & \nabla_{\boldsymbol{P}_{d}} \boldsymbol{F} & 0 & 0 & 0 & 0 & I \\
0 & 0 & 0 & \langle\boldsymbol{\omega}\rangle & 0 & \langle\boldsymbol{v}\rangle & 0 \\
0 & 0 & 0 & 0 & \langle\boldsymbol{s}\rangle & 0 & \langle\boldsymbol{\mu}\rangle
\end{array}\right],
\end{gathered}
$$

The solution of K.K.T optimality conditions can be found by iteratively solving (8). When the candidate solution of bid-based TCED problem occurs at the boundary of the feasible region defined by the transmission constraints (6-e), the electricity price will vary with the location of the bus. The locational marginal price (LMP) at bus $i$ is defined as the least cost to produce/consume one additional MW of real power at the bus i, evaluated at the optimal solution of (8). According to aforementioned descriptions, the LMP at bus i can be determined as follows:

$$
\begin{gathered}
\mathrm{LMP}_{1}=\lambda \\
\mathrm{LMP}_{i}=\lambda-\sum_{l=1}^{N_{l}} \mu_{l} T_{l i}+\sum_{l=N_{l}+1}^{2 N_{l}} \mu_{l} T_{l i} ; i \neq 1
\end{gathered}
$$

Note that bus 1 is assumed to be the reference bus. According to (11), LMP at bus $i$ is composed by two components: (1) incremental cost of generation at the reference bus, and (2) incremental cost of congestion at transmission lines. In the absence of transmission constraints, the dual variable associated with the power balance constraint $\lambda$ gives the wholesale electricity market clearing price.

\section{Non-Cooperative Game of Wholesale Electricity Market Participants}

Strategic bidding behavior of an electricity market participant can be formulated as a BLP problem. In the upper level, the profit of intended market participant is maximized. Obviously, GENCOs and strategic consumers have different objective functions. The objective function of GENCO $\mathrm{j}$ can be defined by:

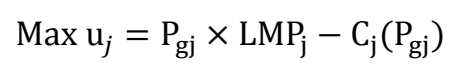

Where bidding strategy of GENCO $\mathrm{j} \mathrm{k}_{\mathrm{j}}$ is decision variable in (12). Also the objective function of strategic consumer $\mathrm{i}$ that participates in energy market can be formulated as follows:

$$
\operatorname{Max~}_{i}=-\frac{1}{2} \alpha_{i} P_{d i}^{2}+\beta_{i} P_{d i}-\mathrm{P}_{\mathrm{di}} \times \mathrm{LMP}_{\mathrm{i}}
$$

Where bidding strategy of LA i $\kappa_{\mathrm{i}}$ is decision variable in (13). In addition, clearing process of wholesale electricity market is embedded into lower level and taken as constraints of the upper level problem. According to aforementioned descriptions, profit maximization of the market participant $\varphi, \varphi \in\left\{1 \ldots \mathrm{N}_{\mathrm{g}}+\mathrm{N}_{\mathrm{d}}\right\}$, is modeled by the following BLP problem:

$$
\operatorname{Max} u_{\phi}
$$

Subject to:

$$
\operatorname{Min} f\left(\boldsymbol{P}_{g}, \boldsymbol{P}_{d}\right)
$$

Subject to: 


$$
\begin{gathered}
\sum_{i=1}^{N_{d}} P_{d i}-\sum_{j=1}^{N_{g}} P_{g j}=0, \\
P_{g j}^{\min } \leq P_{g j} \leq P_{g j}^{\max } ; j=1 \ldots N_{g \prime} \\
P_{d i}^{\min } \leq P_{d i} \leq P_{d i}^{\max } ; i=1 \ldots N_{d}, \\
-F_{l, \text { max }} \leq\left\{f_{l}=\sum_{i=1}^{N} T_{l i}\left(P_{g i}-P_{d i}\right)\right\} \leq F_{l, \text { max }} ; l=1 \ldots N_{l},
\end{gathered}
$$

In (14), the BLP method is employed to model optimal bidding strategy problem from viewpoint of market participant $\varphi$. In the upper level, market participant $k$ maximizes its profit and in the lower level ISO will clear the market by solving the bid-based TCED problem. In this paper, optimal bidding strategy of market participant $\varphi$ is calculated based on the fictitious play approach. In the fictitious play approach, optimal bidding strategy of market participant $\varphi$ will be calculated by an iterative method, which starts with an initial guess for the strategic variables and using the sensitivity function to successively update the strategic variable of market participant $\varphi, k_{\varphi}$, when the bidding strategies of its rival participant $\mathbf{k}_{-\varphi}$ are fixed on their initial values. The process of updating the bidding strategy of GENCO $\mathrm{j}$ is repeated until convergence occurs. It should be noted that due to oligopolistic nature of electricity market, player $\varphi$ cannot optimize its profit by its own, but it must consider what the other participants will do. As all rivals of player $\varphi$ try to maximize their profits, optimal bidding strategy problem can be considered as an interactive optimization. Non-cooperative GT provides a systematic mechanism to determine the equilibrium of the market participants' oligopolistic competition. The normal-form representation of a game denotes non-cooperative games by the triple $\langle\mathrm{M}, \mathrm{K}, \mathrm{U}\rangle$; where $\mathrm{M}$ is the number of players, $\mathrm{Kj}$ is the strategy space (all available strategies) of player $\mathrm{j}, \mathrm{K}=\mathrm{K}_{1} \times \ldots \times \mathrm{K}_{\mathrm{j}} \times \ldots \times \mathrm{K}_{\mathrm{M}}$ represents available strategies of all players, $\mathbf{k}=\left(\mathrm{k}_{1}, \ldots, \mathrm{k}_{\mathrm{j}}, \ldots, \mathrm{kM}\right)$ is strategy profile of the game (combination of strategies chosen by players), and $U_{i}$ is a function mapping each strategy profile of the game to a real-valued payoff for player i. For the sake of simplicity it is assumed that each player has complete information about payoff functions of rival players (game with complete information). GT proposes that if all players act rationally, non-cooperative game of selfish players eventually will lead to NE. NE could be called strategically stable or self-enforcing, because no single player wants to change its bidding strategy. In a non-cooperative game the strategy profile $\mathbf{k}^{*}=\left(k_{1}^{*} \ldots k_{j}^{*} \ldots k_{M}^{*}\right)$ is NE, if for every player $\mathrm{j}$ the strategy $k_{j}^{*}$ is the best response to the strategies adopted by rival GENCOs $\boldsymbol{k}_{-j}^{*}$. Thus, for every player $\mathrm{j} \in \mathrm{N}, k_{j}^{*}$ solves:

$$
\operatorname{Max} \mathrm{U}_{\mathrm{j}}\left(k_{j}, \boldsymbol{k}_{-j}^{*}\right)
$$

Where the strategy of player $j \mathrm{kj}$ is decision variable in (15). In (15), the payoff of GENCO $\mathrm{j}$ is function of all GENCOs' bidding strategies. The NE, $\mathbf{k}^{*}$, is obtained by simultaneous solving (12) for all GENCOs have participated in the market. It is worth noting that the existence and uniqueness of NE is not guaranteed in this game. This game may have a NE, several NEs, or none at all. The proposed algorithm will find one equilibrium point, as long as the NE of the problem exists; when multiple NEs exist, it will find a local equilibrium point [13].

\section{Case Study and Simulation Results}

\subsection{Illustrative Case Studies on IEEE 9-Bus Test System}

To provide some intuition about strategic bidding behaviors of market participants, in this section the proposed approach is applied to IEEE 9 bus test system. There are 3 GENCOs participating in the energy market; their generation characteristics are listed in Table 1 . Note that the generator at node $i$ is labeled as GENCO $i$. In following case studies, it is assumed that all GENCOs behave strategically in energy market, otherwise specified. Also there are 3 LAs participating in the energy market. These LAs, which are placed at buses 5, 7, and 9, are labeled as $D_{1}, D_{2}$, and $D_{3}$, respectively. True marginal revenue of all LAs are assumed to be equal; inverse demand function of 
$\mathrm{LA} \mathrm{i}$ is $\mathrm{MD}_{\mathrm{i}}=-0.04 \mathrm{P}_{\mathrm{di}}+20$, for $\mathrm{i}=\{1,2,3\}$. The convenience of this assumption is a better interpretation of the LAs' behaviors. Additionally, IEEE 9-bus test system consists of 9 transmission lines. A lossless DC model is used to consider the transmission network. The data related to transmission network is given in Table 2. It is assumed transmission lines have large enough capacity, otherwise specified.

In Case 1, 3 GENCOs competing against one another to serve 3 non-strategic LAs in energy market. Optimal bidding strategies of GENCOs and market clearing results are given in Table 3. Note that the non-strategic LAs must accept the prevailing market price 17.27 \$/MWh. According to microeconomic theory, a price taker LA will increase demand up the point where the marginal cost of consumption is equal to the marginal revenue obtained from the consumption. Also the line flows are given in Table 4. Since the transmission constraints are not considered, nodal prices will be same at all buses of this lossless transmission network.

Case 2 has the same input data as Case 1, but the transmission limit for the line joining buses 5 and 6 is set to $20 \mathrm{MW}$; this line is labeled as line 3. In this Case, 3 GENCOs competing against one another to serve 3 non-strategic LAs while the transmission constraint of line 3 limited the transactions. With the transmission constraint enforced, Table 5 summarizes the market outcome and Table 6 gives the line flows. Due to congestion, nodal prices are different throughout the transmission network.

Cases 3 and 4 are designed to study effects of LAs' strategic bidding behaviors on market equilibrium. In these Cases, 3 GENCOs competing against one another to serve 3 strategic LAs, and vice versa. In contrast with Cases 1 and 2, in Cases 3 and 4 LAs play active role in the price setting process. In Case 3, it is assumed transmission lines have large enough capacity. NE and market clearing results for Case 3 are summarized in Table 7. In Case 4, the transmission constraint of line 3 is enforced. The simulation results for Case 4 are given in Table 8.

\subsection{Discussion on Results of IEEE 9-Bus Test System}

The investigation on optimal bidding strategy problem begins with discussion on results of Case 1. As can be seen from Table 3, in Case 1 market share of GENCO 2 (cheapest GENCO) is higher than the GENCOs 1 and 3. According to Tables 1 and III, it can be concluded that with no transmission congestion market share of GENCOs are consistent with their generation costs. Also, due to symmetry between revenue functions of demands 1,2 , and 3 , they get same results in Case 1 . While these are obvious results, they show that proposed method is capable of modeling electricity market behaviors.

To investigate effects of LAs' strategic bidding on market outcome, in Case 3 LAs are assumed to be strategic players, contrary to Case 1 . Comparing Tables 3 and 7 shows that strategic bidding by LAs decrease energy price from 17.27 \$/MWh in Case 1 to 16.45 \$/MWh in Case 3. By observing results of Cases 1 and 3, it can be seen that lower energy price transfer welfare from GENCOs to LAs. According to Tables 3 and 7, strategic bidding behaviors of LAs increase consumer surplus from $279.1 \$ / \mathrm{h}$ in Case 1 to $438.1 \$ / \mathrm{h}$ in Case 3 while reducing producer surplus from 1637 \$/h to $1464 \$ / \mathrm{h}$. Note that, without loss of generality, since revenue functions of all LAs are equal, in Case 3 oligopolistic competition of demand side players is a symmetric game. A game is symmetric if the payoff functions of all players are identical and symmetric in the other players' available strategies. In Case 3 it is impossible to distinguish between LAs. As shown in Table 7, LAs 1, 2, and 3 get same results in Case 3. However, as the decrease in producers' surplus is $13.7 \$ / \mathrm{h}$ more than the increase in consumers' surplus, bidding by strategic LAs decreases the social welfare of market as a whole. The social welfare of market for Cases 1, and 3 are given in Table 9. Also, comparing results of Cases 2 and 4 shows that strategic bidding behaviors of LAs have same effect on market outcome in presence of congestion. Note that Cases 2 and 4 represent identical games, except there are no strategic LAs in Case 2, while, in Case 4, LAs play active role in price setting process. According to Tables 5 and 8, strategic bidding behaviors of LAs in Case 4 decrease LMPs at all buses in comparison with Case 2. As can be expected, the demand side players benefit from lower energy price; comparing Tables 5 and VIII shows that strategic bidding behaviors of LAs increase consumer surplus from $253 \$ / \mathrm{h}$ in Case 2 to $572 \$ / \mathrm{h}$ in Case 4 . In addition, strategic bidding by LAs worsens both producer surplus and 
social welfare of the market. According to Table 9, the social welfare of market decreases from 1902.5 $\$ / \mathrm{h}$ in Case 2 to 1647.1 \$/h in Case 4. Main conclusion that can be drawn from above observations is that strategic bidding from demand side can relieve market power on generation side of the market. As a result, strategic bidding behaviors of LAs increase consumer surplus, and decrease energy price and producer surplus, being in agreement with [17]. Therefore strategic bidding from demand side can be recommended as a measure for the mitigation of market power. On the other hand, it is shown that strategic bidding behaviors of LAs may decrease social welfare of market as a whole. In this situation, strategic bidding behaviors of LAs may not be an attractive policy for mitigating market power of large producers.

\section{Conclusions}

In this paper, strategic bidding behaviors of market players who participate in wholesale electricity market were analyzed theoretically and through market simulations. It was demonstrated that strategic bidding behaviors of LAs mitigate market power of GENCOs. Unfortunately, strategic bidding behaviors of LAs may have the undesirable effect of reducing the social welfare, depending on cost functions of GENCOs and revenue functions of LAs. It was shown that the enforcement of transmission constraints decrease social welfare.

The proposed approach allows market policy-makers to gain access to desirable designs and rules. In addition, this approach can be used to assess market power of suppliers. Also, it is useful in providing insights for investment and planning activities in the context of oligopoly markets.

Table 1. Cost coefficients of generators.

\begin{tabular}{ccc}
\hline Bus \# & a & b \\
\hline 1 & 0.22 & 5 \\
2 & 0.17 & 1.2 \\
3 & 0.25 & 1 \\
\hline
\end{tabular}

Table 2. Transmission network data.

\begin{tabular}{cccccccccc}
\hline Line \# & 1 & 2 & 3 & 4 & 5 & 6 & 7 & 8 & 9 \\
From Bus & 1 & 4 & 5 & 3 & 6 & 7 & 8 & 8 & 9 \\
To Bus & 4 & 5 & 6 & 6 & 7 & 8 & 2 & 9 & 4 \\
Reactance (p.u.) & 0.0 & 0.09 & 0.17 & 0.06 & 0.1 & 0.07 & 0.06 & 0.16 & 0.085 \\
\hline
\end{tabular}

Table 3. Market outcome pertaining to Case 1.

\begin{tabular}{|c|c|c|c|c|c|c|}
\hline G \# & $\mathbf{k}$ & Pg (MW) & $\begin{array}{c}\text { LMP } \\
\text { (\$/MWh) }\end{array}$ & $\operatorname{Cost}(\$ / h)$ & $\begin{array}{c}\text { Revenue } \\
(\$ / \mathbf{h})\end{array}$ & Profit (\$/h) \\
\hline $\mathrm{G}_{1}$ & 1.038 & 52.9 & 17.27 & 572.8 & 914.2 & 341.4 \\
\hline $\mathrm{G}_{2}$ & 1.065 & 88.3 & 17.27 & 768.8 & 1525.2 & 756.4 \\
\hline $\mathrm{G}_{3}$ & 1.045 & 63.4 & 17.27 & 555.3 & 1094.5 & 539.2 \\
\hline D \# & $\kappa$ & Pd (MW) & $\begin{array}{c}\text { LMP } \\
\text { (\$/MWh) }\end{array}$ & $\begin{array}{c}\text { Payment } \\
(\$ / \mathrm{h})\end{array}$ & $\begin{array}{c}\text { Revenue } \\
(\$ / \mathbf{h})\end{array}$ & Profit $(\$ / h)$ \\
\hline $\mathrm{D}_{1}$ & 1 & 68.2 & 17.27 & 1178 & 1271 & 93 \\
\hline $\mathrm{D}_{2}$ & 1 & 68.2 & 17.27 & 1178 & 1271 & 93 \\
\hline $\mathrm{D}_{3}$ & 1 & 68.2 & 17.27 & 1178 & 1271 & 93 \\
\hline
\end{tabular}


Table 4. Line flows pertaining to Case 1.

\begin{tabular}{cccccccccc}
\hline Line \# & 1 & 2 & 3 & 4 & 5 & 6 & 7 & 8 & 9 \\
Flow (MW) & -52.9 & -28.5 & 39.7 & -63.3 & -23.6 & 44.5 & 88.2 & -43.7 & 24.5 \\
\hline
\end{tabular}

Table 5. Market outcome pertaining to Case 2.

\begin{tabular}{|c|c|c|c|c|c|c|}
\hline G \# & $\mathbf{k}$ & Pg (MW) & $\begin{array}{c}\text { LMP } \\
\text { (\$/MWh) }\end{array}$ & Cost $(\$ / h)$ & $\begin{array}{c}\text { Revenue } \\
(\$ / \mathbf{h})\end{array}$ & Profit (\$/h) \\
\hline $\mathrm{G}_{1}$ & 1.058 & 54.2 & 17.91 & 594.4 & 971.2 & 376.8 \\
\hline $\mathrm{G}_{2}$ & 1.105 & 83 & 16.92 & 684.9 & 1403.7 & 718.8 \\
\hline $\mathrm{G}_{3}$ & 1.206 & 50.8 & 16.22 & 366.7 & 823.5 & 456.8 \\
\hline D \# & $\kappa$ & Pd (MW) & $\begin{array}{c}\text { LMP } \\
(\$ / M W h)\end{array}$ & $\begin{array}{c}\text { Payment } \\
(\$ / \mathbf{h})\end{array}$ & $\begin{array}{c}\text { Revenue } \\
(\$ / \mathrm{h})\end{array}$ & Profit (\$/h) \\
\hline $\mathrm{D}_{1}$ & 1 & 42.8 & 18.29 & 783 & 819.6 & 36.7 \\
\hline $\mathrm{D}_{2}$ & 1 & 84.4 & 16.62 & 1403.1 & 1545.6 & 142.5 \\
\hline $\mathrm{D}_{3}$ & 1 & 60.8 & 17.57 & 1067.6 & 1141.5 & 73.9 \\
\hline
\end{tabular}

Table 6. Line flows pertaining to Case 2.

\begin{tabular}{cccccccccc}
\hline Line \# & 1 & 2 & 3 & 4 & 5 & 6 & 7 & 8 & 9 \\
Flow (MW) & -54.2 & -22.8 & 20 & -50.8 & -30.8 & 53.6 & 83 & -29.4 & 31.4 \\
\hline
\end{tabular}

Table 7. Market outcome pertaining to Case 3.

\begin{tabular}{|c|c|c|c|c|c|c|}
\hline G \# & $\mathbf{k}$ & $\operatorname{Pg}(\mathrm{MW})$ & $\begin{array}{c}\text { LMP } \\
\text { (\$/MWh) }\end{array}$ & $\operatorname{Cost}(\$ / h)$ & $\begin{array}{c}\text { Revenue } \\
(\mathbf{\$} / \mathbf{h})\end{array}$ & Profit (\$/h) \\
\hline $\mathrm{G}_{1}$ & 1.035 & 49.5 & 16.45 & 517.1 & 814.2 & 297.1 \\
\hline $\mathrm{G}_{2}$ & 1.062 & 84.1 & 16.45 & 701.4 & 1382.5 & 681.1 \\
\hline $\mathrm{G}_{3}$ & 1.043 & 60.3 & 16.45 & 505.7 & 991.8 & 486.1 \\
\hline D \# & $\kappa$ & Pd (MW) & $\begin{array}{c}\text { LMP } \\
(\$ / M W h)\end{array}$ & $\begin{array}{c}\text { Payment } \\
(\$ / \mathrm{h})\end{array}$ & $\begin{array}{c}\text { Revenue } \\
(\$ / \mathbf{h})\end{array}$ & Profit (\$/h) \\
\hline $\mathrm{D}_{1}$ & 0.94 & 64.6 & 16.45 & 1062.8 & 1208.9 & 146.1 \\
\hline $\mathrm{D}_{2}$ & 0.94 & 64.6 & 16.45 & 1062.8 & 1208.9 & 146.1 \\
\hline $\mathrm{D}_{3}$ & 0.94 & 64.6 & 16.45 & 1062.8 & 1208.9 & 146.1 \\
\hline
\end{tabular}

Table 8. Market outcome pertaining to Case 4 .

\begin{tabular}{|c|c|c|c|c|c|c|}
\hline G \# & $\mathbf{k}$ & Pg (MW) & $\begin{array}{c}\text { LMP } \\
(\$ / M W h)\end{array}$ & Cost (\$/h) & $\begin{array}{c}\text { Revenue } \\
(\mathbf{\$} / \mathbf{h})\end{array}$ & Profit (\$/h) \\
\hline $\mathrm{G}_{1}$ & 1.05 & 46.8 & 16.07 & 475.7 & 752.7 & 277 \\
\hline $\mathrm{G}_{2}$ & 1.085 & 70.9 & 14.38 & 512.3 & 1019.5 & 507.2 \\
\hline $\mathrm{G}_{3}$ & 1.164 & 42.2 & 13.2 & 260.3 & 556.8 & 296.5 \\
\hline D \# & $\kappa$ & Pd (MW) & $\begin{array}{c}\text { LMP } \\
\text { (\$/MWh) }\end{array}$ & $\begin{array}{c}\text { Payment } \\
(\$ / \mathbf{h})\end{array}$ & $\begin{array}{c}\text { Revenue } \\
(\$ / \mathbf{h})\end{array}$ & Profit (\$/h) \\
\hline $\mathrm{D}_{1}$ & 0.878 & 24.6 & 16.7 & 410.8 & 480 & 69.2 \\
\hline $\mathrm{D}_{2}$ & 0.776 & 52.6 & 13.89 & 730.4 & 996.6 & 226.2 \\
\hline $\mathrm{D}_{3}$ & 0.928 & 82.7 & 15.48 & 1281.1 & 1517.8 & 236.7 \\
\hline
\end{tabular}


Table 9. Market social welfare.

\begin{tabular}{ccccc}
\hline Case \# & 1 & 2 & 3 & 4 \\
\hline SW (\$/h) & 1916.1 & 1860.7 & 1902.5 & 1647.1 \\
\hline
\end{tabular}

\section{References}

1. Moshari, A.; Yousefi, G.R.; Ebrahimi, A.; Haghbin, S. Demand-side behavior in the smart grid environment. Innovative Smart Grid Technologies Conference Europe (ISGT Europe), Gothenberg, Sweden; IEEE, 11-13 Oct. 2010.

2. Khodaei, A.; Shahidehpour, M.; Mahramirad, S. SCUC with Hourly Demand Response Considering Inter-temporal Load Characteristics. IEEE Trans. on Smart Grid Sept. 2011, 2, 564-571.

3. Marulanda, G.A.; Valenzuela, J.G.; Salazer, H. An assessment of the impact of a demand response program on the Colombian day-ahead electricity market. Transmission \& Distribution Conference and Exposition, Meddelin, Colombia; IEEE, 10-13 Sept. 2014.

4. Parvania, M.; Fotuhi-Firuzabad, M.; Shahidehpour, M. ISO's Optimal Strategies for Scheduling the Hourly Demand Response in Day-Ahead Markets. Power \& Energy Society General Meeting, Denver, Co, USA; IEEE, 26-30 July 2015.

5. Wang, J.; Kennedy, S.; Kirtley, J. A new wholesale bidding mechanism for enhanced demand response in smart grids. Innovative Smart Grid Technologies (ISGT), Gaithersburg, MD, USA; IEEE, 19-21 Jan. 2010.

6. Albadi, M.H.; El-Saadany, E.F. A summary of demand response in electricity markets. Electric Power System Research May 2008, 78, 1989-1996.

7. Su, C.; Kirschen, D.S. Direct Participation of Demand-Side in a Pool-Based Electricity Market. Power System Technology Oct. 2007, 31.

8. Yoo, T.H.; Park, H.; Lyn, J; Park, J. Determining the Interruptible Load with Strategic Behavior in a Competitive Electricity Market. Energies 2015, 8, 257-277.

9. Manshadi, S; Khodayar, M.E. A Hierarchical Electricity Market Structure for the Smart Grid Paradigm. IEEE Trans. on Smart Grid July 2016, 2, 1866-1875.

10. Iria, J.P.; Soares, F.J.; Bessa, R.J. Optimized Demand Response Bidding in the Wholesale Market under Scenarios of Prices and Temperatures. PowerTech, Eindhoven, Netherlands; IEEE, 29 June-2 July 2015.

11. Zhang, Xiao-Ping. Restructured Electric Power Systems: Analysis of Electricity Markets with Equilibrium Models; Wiley-IEEE Press: New York, USA, 2010.

12. Morey, M.J. Power Market Auction Design: Rules and Lessons In Market-based Control for the New Electricity Industry; Edison Electric Institute, USA, 2001.

13. Taheri, I.; Rashidinejad, M; Badri, A.; Rahimi-Kian, A. Analytical Approach in Computing Nash Equilibrium for Oligopolistic Competition of Transmission-Constrained GENCOs. IEEE Systems Journal Journal April 2014, 99.

14. Li, T.; Shahidehpour, M. Strategic Bidding of Transmission-Constrained GENCOs with Incomplete Information. IEEE Trans. Power Systems Feb. 2005, 20, 437-447.

15. Kirschen, D.S. Demand-Side View of Electricity Markets. IEEE Trans. Power Systems May 2003, 18, 520-527.

16. Thimmapuram, P.R.; Kim, J. Consumers' Price Elasticity of Demand Modeling With Economic Effects on Electricity Markets Using an Agent-Based Model. IEEE Trans. Smart Grid March 2013, 4, 390-397.

17. Kirschen, D.S.; Strbac, G.; Cumperayot, P.; Mendes, D. Factoring the Elasticity of Demand in Electricity Prices. IEEE Trans. Power Systems May 2000, 15, 612-617.

18. Kazempour, S.J.; Conejo, A.J.; Ruiz, C. Strategic Bidding for a Large Consumer. IEEE Trans. Power Systems March 2015, 30, 848-856.

19. Srinivasan, D.; Trung, L.T.; Singh, C. Bidding and Cooperation Strategies for Electricity Buyers in Power Markets. IEEE Systems Journal July 2015, 99.

20. Herranz, R.; Roque, A.M.S.; Villar, J; Campos, F.A. Optimal Demand-Side Bidding Strategies in Electricity Spot Markets. IEEE Trans. Power Systems August 2012, 27, 1204-1213.

21. Kardakos, E.G.; Simoglou, C.K.; Bakirtzis, A.G. Optimal bidding strategy in transmission-constrained electricity Markets. Electric Power Syst. Research Jan. 2014, 109, 141-149.

22. Badri, A.; Rashidinejad, M. Security Constrained Optimal Bidding Strategy of GENCOs in Day-Ahead Oligopolistic Power Markets: A Cournot-Based Model. Electrical Engineering June 2013, 95, 63-72. 
23. Petoussis, S.G.; Zhang, X.P.; Godfrey, K.R. Electricity Market Equilibrium Analysis based on Nonlinear Interior Point Algorithm with Complementarity Constraints. IET Gener. Trans. Distrib. July 2007, 1, 603-612.

24. Petoussis, A.G.; Zhang, X.P.; Petoussis, S.G.; Godfrey, K.R. Parameterization of Linear Supply Functions in Nonlinear AC Electricity Market Equilibrium Models-Part I: Literature Review and Equilibrium Algorithm. IEEE Trans. Power Systems May 2013, 28, 650-658.

25. Boldick, Ross. Applied Optimization: Formulation and Algorithms for Engineering Systems; Cambridge University Press, 2006.

26. Luenberger, David G., Ye, Yinyu. Linear and Nonlinear Programming; Springer Sxcience+Business Media, LLC, 2008. 